\title{
Reflexões e conhecimentos evidenciados por professores que estudam área de figuras planas
}

\author{
Reflections and knowledge evidenced by teachers studying area of flat figures \\ Angelica da Fontoura Garcia Silva ${ }^{1}$ \\ Susana Maris França da Silva ${ }^{2}$ \\ Maria Elisa Esteves Lopes Galvão ${ }^{3}$
}

\begin{abstract}
Resumo
Apresenta-se, neste artigo, um estudo cujo objetivo é discutir e compreender o processo de (re)significação dos conhecimentos profissionais dos seus participantes concernente às discussões e às reflexões explicitadas por um grupo de professores que leciona matemática para os anos iniciais do Ensino Fundamental. Os professores estudaram o cálculo de área de figuras planas por meio da utilização de quadriculados. Fundamenta-se nos estudos de Zeichner e Serrazina para discutir a reflexão sobre a prática e, em Ball, Thames e Phelps, para analisar a (re)significação dos conhecimentos dos profissionais envolvidos. Os dados analisados foram coletados durante os encontros do grupo na própria escola na qual os participantes lecionavam. Por meio das análises das discussões ocorridas, foi possível observar que os professores ampliaram o conhecimento comum e especializado do conteúdo, especialmente em relação às estratégias de cálculo da área, e ainda passaram a utilizar reconfiguração das figuras e as fórmulas de área com maior facilidade. O apoio mútuo permitiu que eles identificassem suas próprias necessidades e, então, modificassem suas análises acerca das estratégias para o cálculo de área a serem adotadas.
\end{abstract}

Palavras-chave: Grupo de estudos, Conhecimento profissional docente, Área de figuras planas

\begin{abstract}
In this article we present a study whose objective is to discuss and understand the process of (re) meaning of the professional knowledge of its participants concerning the discussions and reflections explained by a group of teachers who teach mathematics for the initial years of the Fundamental Education. The teachers studied the area calculation of flat figures through the use of squaring. It is based on the studies of Zeichner and Serrazina to discuss the reflection on the practice and, in Ball, Thames and Phelps, to analyze the (re) significance of the knowledge of the professionals involved. The data analyzed were collected during the group meetings at the school where the participants taught. Through the analyses of the discussions that took place, it was possible to observe that the teachers expanded the common and specialized knowledge of the content, especially in relation to the strategies of calculation of the area, and they still used reconfiguration of the figures and the formulas of
\end{abstract}

Submetido em: 18/06/2018 - Aceito em: 24/08/2020 - Publicado em: 18/12/2020

${ }^{1}$ Doutora Angélica da Fontoura Garcia Silva, Professora da Universidade Anhanguera de São Paulo - UNIAN Brasil. Email: angelicafontoura@gmail.com. ORCID: http://orcid.org/0000-0002-2435-9240

2 Doutoranda Susana Maris França da Silva, Professora da Universidade Adventista de São Paulo - UNASP Brasil. Email: susana_ditty@hotmail.com. ORCID: https://orcid.org/0000-0001-8457-8157

${ }^{3}$ Doutora Maria Elisa Esteves Lopes Galvão, Professora da Universidade Anhanguera de São Paulo - UNIAN Brasil. Email: elisa.gal.meg@gmail.com. ORCID: http://orcid.org/0000-0003-3899-711X 
DOI: $10.20396 /$ zet.v28i0.8652733

area with greater ease. Mutual support allowed them to identify their own needs and then modify their analyses of the strategies for area calculation to be adopted.

Keywords: Study group, Teaching professional knowledge, Flat figure area

\section{Introdução}

Neste artigo apresentamos uma análise de discussões e reflexões ocorridas no âmbito escolar com a participação de um grupo de estudos de professores que leciona matemática para os anos iniciais do Ensino Fundamental. As participantes desta investigação estudaram e refletiram de forma compartilhada acerca da temática área de figuras planas e seu ensino para os anos iniciais do Ensino Fundamental a fim de discutir e compreender o processo de (re)significação dos seus conhecimentos profissionais.

A relevância do tema no currículo de Matemática é notória tanto por sua aplicação prática como pela compreensão de outros conceitos matemáticos. Tal fato está explicitamente considerado nas orientações curriculares brasileiras, tais como nos Parâmetros Curriculares Nacionais - PCN - (Brasil, 1997) e na Base Nacional Comum Curricular - BNCC - (Brasil, 2018), por exemplo. Neles a ideia de área aparece quando são descritas tanto as habilidades da unidade temática (ou bloco ${ }^{4}$ ) Grandezas e Medidas quanto as relativas a Números (ou Números e Operações ${ }^{5}$ ). Nesses dois documentos, espera-se o desenvolvimento dessa ideia para introduzir os significados não só da multiplicação, mas também o de configuração retangular da multiplicação, para a compreensão da ideia de medida a partir e figuras desenhadas em malhas quadriculadas e comparação de perímetros e áreas de duas figuras sem uso de fórmulas.

Nesse contexto, referenciados em Gimeno Sacristan (2000), consideramos a relevância do papel do professor diante das orientações curriculares, uma vez que ele exerce um papel fundamental em pelo menos quatro dos seis níveis de desenvolvimento curricular. É o professor que molda o currículo, implementa-o e, muitas vezes, avalia os efeitos produzidos. Analisando as indicações curriculares para o ensino de área de figuras planas, julgamos importante para a atuação profissional do professor que ele compreenda que o cálculo de área em malhas quadriculadas pressupõe muito mais do que "contar quadradinhos" ou utilizar-se da compensação empírica quadrado a quadrado.

Além de olhar para os documentos curriculares, apoiamo-nos também em pesquisas que discutem os processos de ensino e de aprendizagem da temática e sobre os conhecimentos de professores e futuros professores de áreas de figuras planas. Clements e Stephan (2004) discutem questões relativas à compreensão do conceito aqui investigado. Os autores avaliaram tipos de tarefa que podem favorecer o entendimento a respeito de área de figuras planas e concluíram que a prática recorrente de contagem simples de unidades para

\footnotetext{
${ }^{4}$ Grandezas e Medidas aparecem nos PCN (Brasil, 1997) e na BNCC (Brasil, 2018). No primeiro documento, é designada como um bloco, já na BNCC é tida como uma Unidade Temática da Matemática.

${ }^{5}$ Números é a designação de uma das unidades temáticas da BNCC (2018). Nos PCN (1997), é tratado no bloco Números e Operações.
} 
encontrar área "é uma receita para o desastre" (p.20). Consideram que, para o ensino dessa temática, os professores devem levar em conta a necessidade de os estudantes:

(a) construírem a ideia de unidades de medida (incluindo o desenvolvimento de um senso de medição para unidades padrão; por exemplo, encontrar objetos comuns no ambiente de uma medida unitária); (b) terem muitas experiências cobrindo quantidades com unidades de medida apropriadas e contando essas unidades; (c) estruturarem espacialmente o objeto a ser medido (por exemplo, ligando a contagem por grupos à estrutura de matrizes retangulares; construindo conceitos bidimensionais); e eventualmente (frequentemente nos graus intermediários), (d) construírem a relação inversa entre o tamanho de uma unidade e o número de unidades usadas em uma medida particular; e (e) construírem um espaço bidimensional e relações multiplicativas correspondentes. (p.20, tradução nossa) ${ }^{6}$

Assim como Clements e Stephan (2004), entendemos que o cálculo de área é bastante complexo e, portanto, é preciso que o profissional que vai ensiná-lo também saiba, dentre outras habilidades, como calcular a medida da área, analisando a figura como um todo, valendo-se do seu cálculo por meio da reunião de figuras, da equivalência de áreas, da composição e da decomposição de figuras.

No tocante aos conhecimentos de futuros professores e professores que lecionam matemática para os anos iniciais a respeito do cálculo de área de figuras planas, nos pautamos em investigações como as de Baturo e Nason (1996), Garcia Silva et al. (2013) e as de Gomes et al. (2018).

Baturo e Nason (1996) avaliaram os conhecimentos de futuros professores acerca de medida de áreas por meio de entrevistas individuais durante a resolução de oito tarefas criadas para a pesquisa. Ao proporem tais tarefas, os autores procuravam identificar conhecimento concreto e computacional sobre o conceito de área e verificaram limitações no repertório de conhecimento concreto, uma vez que os participantes apresentaram dificuldades em relacionar as regras ou as fórmulas com as experiências concretas. Por outro lado, Garcia Silva et al. (2013) e Gomes et al. (2018), ao investigarem conhecimentos de professores experientes que lecionavam matemática para os anos iniciais, constataram que as estratégias utilizadas pelos participantes de um processo de formação continuada eram focadas sobretudo na contagem e na reorganização de quadradinhos o que, a nosso ver, poderia ser um fator limitador ao ensino da temática.

Dessa forma, considerando a complexidade inerente à construção de saberes docentes, cremos ser relevante analisar a (re)significação de conhecimentos profissionais de professores

\footnotetext{
6 a) construct the idea of measurement units (including development of a measurement sense for standard units; for example, finding common objects in the environment that have a unit measure); (b) have many experiences covering quantities with appropriate measurement units and counting those units; (c) spatially structure the object they are to measure (e.g., linking counting by groups to the structure of rectangular arrays; building two-dimensional concepts); and eventually (often in the intermediate grades), (d) construct the inverse relationship between the size of a unit and the number of units used in a particular measurement; and (e) construct two-dimensional space and corresponding multiplicative relations.
} 
a respeito dos modelos intuitivos para o cálculo de área em malhas quadriculadas e seu ensino, a partir do trabalho com um grupo de professores que ensinam, estudam e refletem sobre área de figuras planas na própria escola em que trabalham. Como neste artigo analisaremos a atenção dada a essa temática no trabalho realizado em um grupo de estudos, fundamentaremos nossa análise nas investigações que discutem questões relativas a esse tipo de formação continuada, no conhecimento profissional docente e na reflexão sobre a prática que apresentaremos a seguir.

\section{Marco teórico}

Para analisar os momentos de reflexões sobre as práticas de forma coletiva, vamos nos apoiar em Zeichner (1993, 2008). Entendemos, assim como esse autor, ser fundamental que os professores assumam uma atitude reflexiva em relação às condições sociais que influenciam o ensino e a forma como ele, efetivamente, acontece no âmbito da sala de aula. Acreditamos que a constituição de grupos de estudos na própria escola em que lecionam os participantes pode potencializar tal atitude. Faz-se igualmente necessário analisar quais seriam as teorias práticas dos professores, como o descrito por Zeichner (1993), para quem “os professores estão sempre a teorizar, à medida que são confrontados com vários problemas pedagógicos, tais como a diferença entre suas expectativas e os resultados" (p.21). Assim sendo, comungamos com a ideia do autor acerca de ser de fundamental importância ouvir o que o professor tem a dizer, para que ele, em parceria com os colegas do grupo, expresse suas necessidades, e juntos analisem suas falhas e apoiem-se mutuamente. Isso, a nosso ver, poderá favorecer a melhor compreensão dos conteúdos que precisa ensinar e as possibilidades de desenvolver-se profissionalmente.

As ideias apresentadas por Zeichner (2008) se aproximam dos estudos de Ball, Thames e Phelps (2008), os quais também respaldarão esta investigação, quando afirmam que a base de conhecimentos do professor utilizada para o ensino é sustentada por uma teia de relações.

Ball et al. (2008), fundamentados em Shulman (1986), detalham, com base nas análises das demandas matemáticas do ensino investigadas pelo grupo, uma interpretação dos conhecimentos necessários aos professores de Matemática. Os autores separam e explicitam um detalhamento para o conhecimento do conteúdo específico descrito por Shulman, em três categorias: Common Content Knowledge (CCK); Specialized Content Knowledge (SCK) e Horizon Content Knowledge (HCK) que podem ser traduzidos por Conhecimento comum do conteúdo, Conhecimento especializado do conteúdo e Conhecimento do conteúdo no horizonte. Neste artigo analisaremos especialmente duas dessas categorias: Conhecimento comum do conteúdo e Conhecimento especializado do conteúdo, os quais serão descritos a seguir.

Ball et al. (2008) declaram que o Conhecimento comum do conteúdo (CCK) refere-se ao conhecimento de conteúdos matemáticos que todos os profissionais, professores ou não, que estudam a Matemática, deveriam saber. Essa categoria envolve os conhecimentos que 
levam o professor a, por exemplo, reconhecer algoritmos eficientes para resolver determinadas situações ou mesmo desenvolver procedimentos de cálculo, identificar quando o livro didático dá uma definição inadequada, ser capaz de usar termos e notações corretamente, quando fala ou escreve na lousa. Segundo os autores, é um conhecimento importante, mas somente ele não basta para efetivar o ensino, uma vez que envolve "o conhecimento que os professores precisam para serem capazes de fazer o trabalho que eles atribuem aos seus alunos ${ }^{7 ”}$ (Ball et al., 2008, p. 395, tradução nossa). Esse conhecimento pode estar relacionado ao reconhecimento, por parte do professor, de um erro cometido por seu aluno quando calcula a área de um polígono qualquer, por exemplo.

O Conhecimento especializado do conteúdo (SCK) é aquele que requer do professor um conhecimento de conceitos e procedimentos mais aprofundado do que aquele que é exigido ao aluno. Para os autores, esse é um conhecimento exclusivo do profissional professor - "conhecimento distintamente matemático, mas não é necessariamente conhecimento matemático familiar aos matemáticos" ${ }^{8 ”}$ (Ball et al., 2008, p. 394, tradução nossa) - e essencial à realização do ensino, por causa disso intimamente relacionado com a prática. O professor deve, segundo os autores, estar habilitado a reconhecer as diferentes formas de expressar a resolução de uma determinada situação-problema. Por conseguinte, o olhar do professor estará voltado para analisar, reconhecer e avaliar as respostas dos estudantes, confrontar todos os tipos de soluções dos estudantes, descobrir, do ponto de vista da matemática, o que os alunos têm feito.

No tocante à relação entre a ampliação da base de conhecimentos e a reflexão sobre a prática, apoiamo-nos em estudos de Serrazina (1999, 2012). A autora, ao pesquisar a capacidade de reflexão dos professores de Matemática, observou que a capacidade de refletir a própria prática

ocorre quando os professores ganham autoconfiança e são capazes de reflectir nas suas práticas. Isto pressupõe um elevado grau de conscientização que os ajude a reconhecer as suas falhas e fraquezas e a assumir um forte desejo de as ultrapassar. (Serrazina, 1999, p. 163)

Quanto aos conhecimentos destinados ao ensino, Serrazina (2012), apoiada nos estudos de Ball, afirma que os professores que lecionam matemática para os anos iniciais necessitam "ter uma compreensão profunda da matemática que ensinam que não se limite a um conhecimento tácito do tipo saber fazer, mas que se traduza num conhecimento explícito" (p. 282) e, para tanto, sugere que os próprios docentes sintam-se "envolvidos em experiências de aprendizagem de modo que experimentem o conhecimento e a 'vivência pessoal' dos processos e da natureza da actividade matemática" (p. 282, ênfase no original). No tocante a essas experiências, consideramos também que, no seio de um grupo que estuda acerca dos

\footnotetext{
7 "it is the knowledge teachers need in order to be able to do the work that they are assigning their students".

${ }^{8}$ is distinctly mathematical knowledge but is not necessarily mathematical knowledge familiar to mathematicians (Ball el al., 2008, p. 394).
} 
DOI: $10.20396 /$ zet.v28i0.8652733

conteúdos a serem ensinados, o professor terá condições mais favoráveis para que ocorra, igualmente, a reflexão sobre a prática. Isso posto, julgamos ser o grupo de estudos um ambiente propício a essas experimentações.

\section{Procedimentos metodológicos}

A pesquisa aqui apresentada, de natureza qualitativa, contou com a participação de quatro professoras que lecionam matemática para os anos iniciais em uma escola particular, localizada em uma cidade da grande São Paulo - Brasil. Para preservar suas identidades, serão identificadas, na pesquisa, por nomes de flores: professoras Acácia, Violeta, Jasmim e Watsonia. Todas concluíram o ensino superior em Pedagogia em diferentes momentos: duas delas têm menos de 2 anos de atuação profissional, e as outras duas atuam há 14 e 32 anos, respectivamente. Após uma análise das respostas dadas a um questionário, que se constituiu uma investigação inicial sobre as concepções e os conhecimentos dos professores relativos ao conceito de área e seu ensino, conduzimos sessões de estudo sobre o tema. Buscamos elementos para investigar como se dá a ampliação da base de conhecimentos para o ensino a respeito de área de figuras planas, mediante estudos realizados em grupo na própria escola.

As informações foram coletadas durante as sessões de estudo por meio de registros escritos da resolução das atividades pelos professores e vídeo gravações das sessões de estudo do grupo para posterior transcrição.

Para este artigo, analisamos três das sessões de estudo das quais todas as professoras participaram: numa sessão solicitamos a resolução de uma questão que tratava do cálculo da área de três figuras associadas a uma malha quadriculada e, nas demais, essas questões foram discutidas a partir da análise das resoluções apresentadas pelas professoras.

\section{Apresentação e análise dos dados}

Os encontros dedicados às análises e às reflexões foram orientados pela avaliação dos dados coletados por meio dos protocolos que continham a resolução das participantes a um questionário inicial.

No primeiro encontro de trabalho, foram solicitadas explicações sobre a forma de resolução, por elas adotada, para as áreas das figuras dadas. Analisaremos e discutiremos, na sequência, os registros das resoluções e das reflexões acontecidas durante o processo formativo.

\section{Questionário inicial: análise das resoluções apresentadas pelas professoras}

Na primeira questão proposta no questionário inicial, foram apresentadas três figuras, cuja área deveria ser calculada. 
(A)

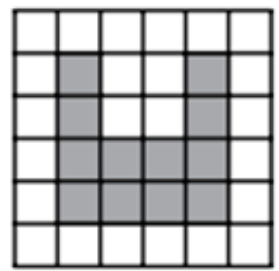

(B)

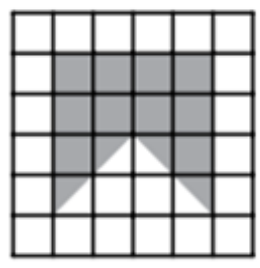

(C)

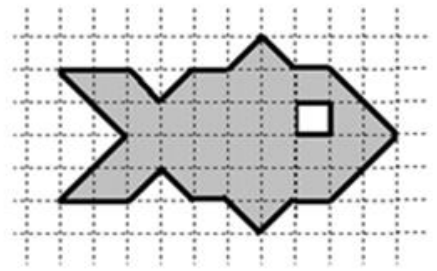

Figura 1 - Situação apresentada no questionário inicial Fonte: Acervo da Pesquisa

$\mathrm{Na}$ retomada das questões, as professoras Jasmim e Violeta afirmaram que, no momento inicial, não conseguiam lembrar o que era área e/ou determinar a medida de área das figuras apresentadas.

A professora Acácia e a professora Watsonia rearranjaram as formas, fazendo, na figura (A), com que cada quadradinho mudasse de lugar até formar uma figura maior "sem buracos" (professora Watsonia). Na figura (B), reagruparam os triângulos para formar um quadrado e, assim, obter uma figura maior fechada que, em suas concepções, seria melhor para determinar a área da figura. A figura (C) foi mais complexa para as professoras, pois elas precisaram rearranjar as "metades" até formar um quadradinho, para então obter uma figura maior "sem buracos" (professora Watsonia), para então conseguir a área total da forma. Elas também perceberam na resolução da figura $(\mathrm{C})$ que essa continuaria com um "buraco", descrito assim pela professora Watsonia, e que elas poderiam fazer a área total menos 1 (quadrado).

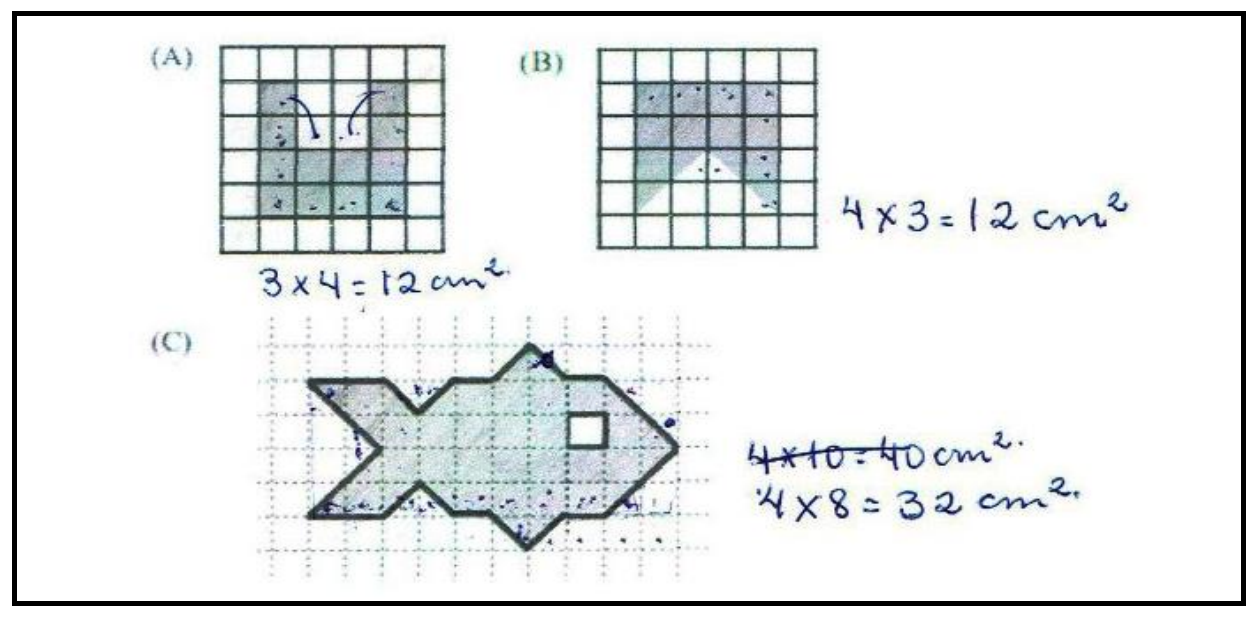

Figura 2 - Protocolo apresentado pela professora Watsonia Fonte: Acervo da pesquisa

A professora Acácia, por sua vez, apenas colocou o valor numérico para cada um dos resultados, preferindo não mencionar nenhuma unidade de medida. 
DOI: $10.20396 /$ zet.v28i0.8652733

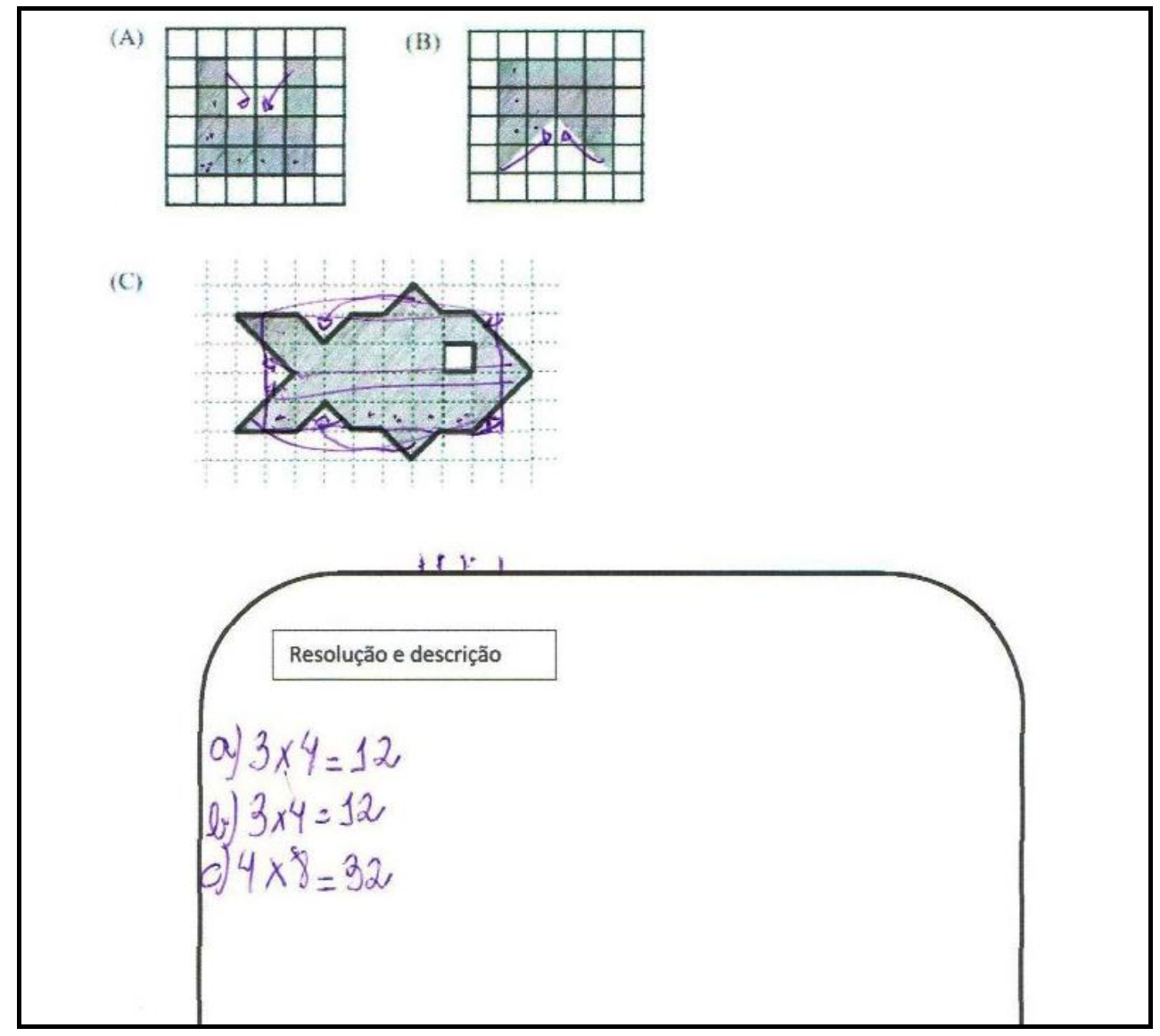

Figura 3 - Protocolo apresentado pela professora Acácia Fonte: Acervo da Pesquisa

Analisando a estratégia utilizada pela professora Acácia, observamos que ela juntou partes das figuras para formar quadradinhos e, depois disso, realizou a contagem. Essa estratégia também foi constatada por Garcia Silva et al. (2013). Tais dados foram utilizados para fomentar as significações e as reflexões do grupo no âmbito da formação.

\section{O grupo reflete sobre as suas resoluções}

Como constatamos, por meio da análise do questionário inicial, que as professoras Acácia e Watsonia rearranjaram a figura, agruparam os triângulos e remanejaram as formas para determinar a medida de área, solicitamos que elas explicassem às demais participantes quais as concepções utilizadas ao calcular a área das figuras. A apresentação das professoras nos levou à confirmação de que as estratégias por elas adotadas no início de nossa pesquisa eram exclusivamente o processo de contagem dos "quadradinhos", conforme podemos verificar nas imagens a seguir (Figura 4). 

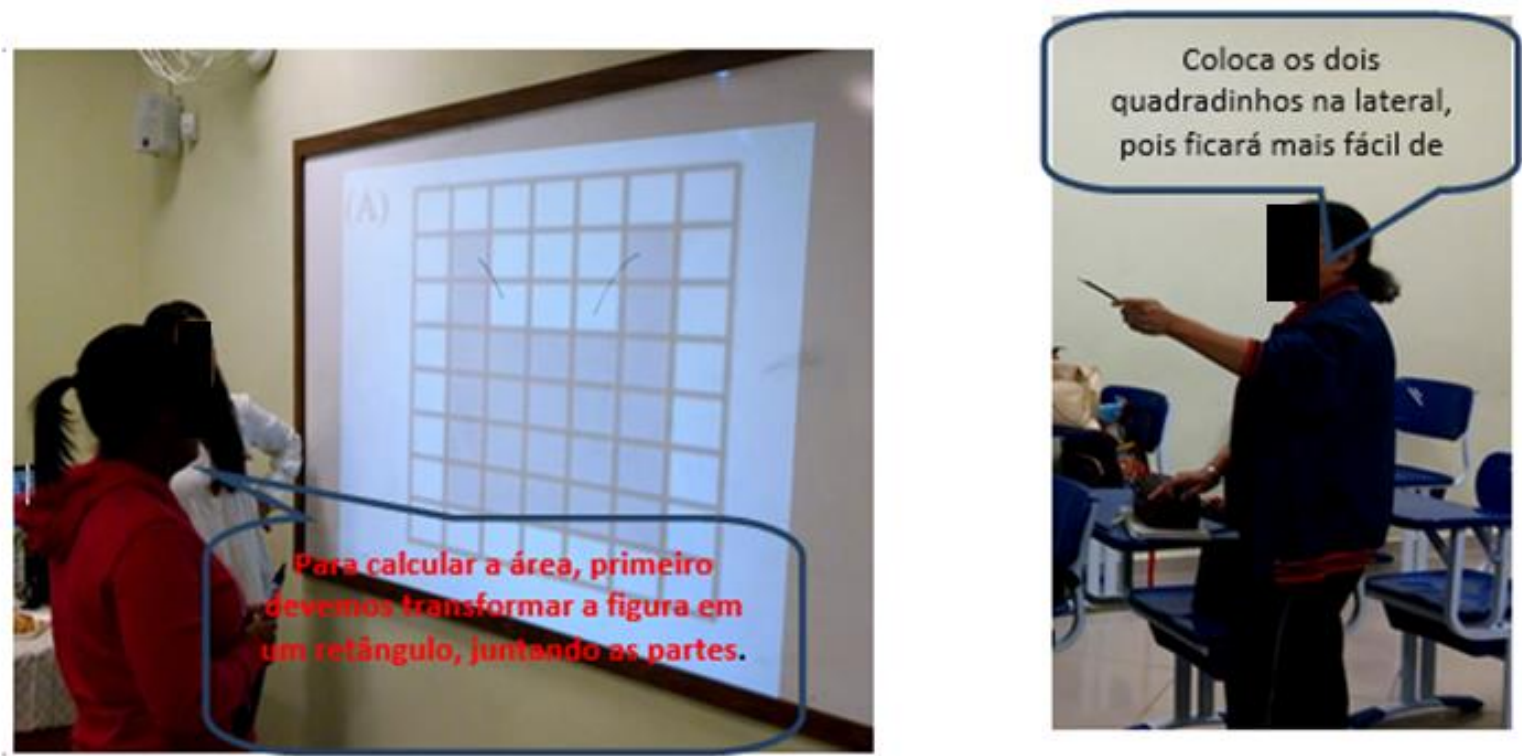

Figura 4 - Atividade proposta para ampliar as concepções sobre área Fonte: Acervo da Pesquisa

Em outra figura, elas novamente demonstraram que estavam se utilizando da contagem e da composição de "quadradinhos" para determinar a medida de área (Figuras 5 e 6), assim como detectado no trabalho de Garcia Silva et al. (2013).

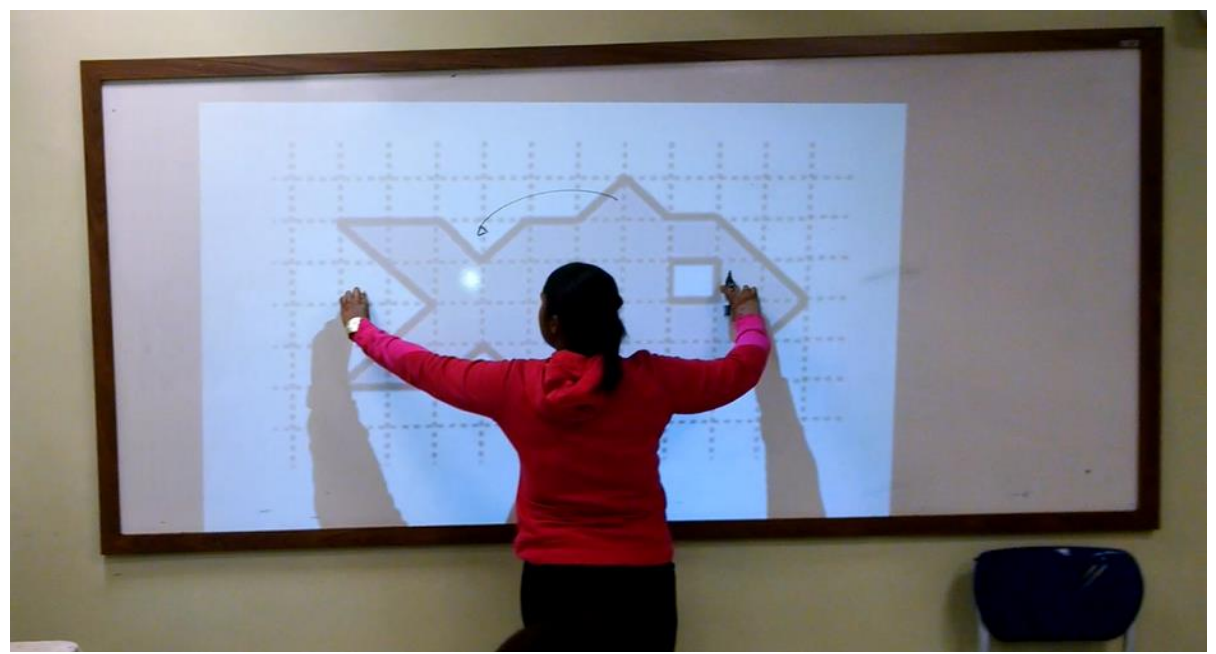

Figura 5 - Professora Acácia mostra sua estratégia para determinar a medida de área Fonte: Acervo da Pesquisa 


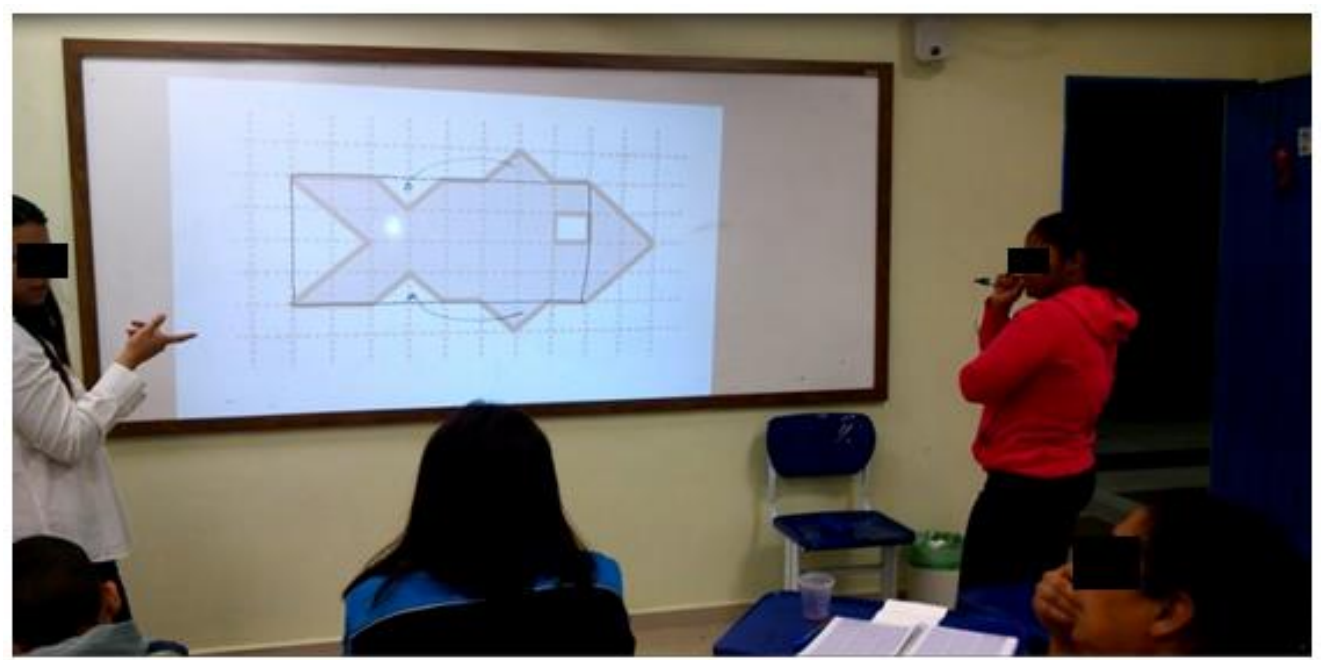

Figura 6 - Professoras são encorajadas a analisar as possibilidades de cálculo para determinar a medida de área Fonte: Acervo da Pesquisa

Nesse momento, observamos que as professoras Violeta e Jasmim ampliaram seus conhecimentos, uma vez que não tinham conseguido calcular a área dessas figuras, quando responderam ao questionário inicial:

Profa. Violeta: Gente, eu não compreendia direito o que era área (referindo-se às perguntas presentes na fase diagnóstica).

Profa. Jasmim: Eu não fazia ideia que era só contar os quadradinhos.

Pesquisador: Para calcular a área, basta contar os quadradinhos, é isso?

Profa. Acácia: Nós contamos por que estava no quadriculado.

Profa. Jasmim: É isso, eu quero saber quantos quadradinhos cabe.

Pesquisador: Isso, então a área está ligada à medida, não acham?

Profa. Violeta: $O$ pior que a gente usa isso no dia a dia, mede área do piso, por exemplo. Lá a gente faz isso, conta quantos pisos cabem no chão da sala, por exemplo.

Profa. Jasmim: Na verdade a gente sabia medir, mas não sabia o que era.

Nesse momento, nas frases iniciais das professoras Violeta, Jasmim e Acácia que se referem à contagem de quadradinhos, notamos indícios de ampliação do conhecimento comum. Provocadas em relação à ideia de medida, as manifestações das professoras Violeta e Jasmim indicam a conscientização da necessidade de avançar na direção do conhecimento especializado do conceito de área como medida, sobretudo quando elas relacionam essa medida a situações cotidianas, sobretudo quando a professora Jasmim afirma: "O pior que a gente usa isso no dia a dia, mede área do piso, por exemplo. Lá a gente faz isso, conta quantos pisos cabem no chão da sala, por exemplo”. Nesse contexto, consideramos que uma maior compreensão de procedimentos de cálculo de área evidência o desenvolvimento de Conhecimento Comum do Conteúdo dessas professoras, já a discussão gerada sobre ideia de medida pode favorecer a ampliação do Conhecimento Especializado deste conteúdo uma vez que, de acordo com Ball et al. (2008), tal entendimento poderia favorecer a realização do ensino. 
DOI: $10.20396 /$ zet.v28i0.8652733

Todavia, ainda havia a forte tendência de utilizar como estratégia somente a contagem dos quadradinhos. Assim, apresentamos, na sequência, três novas figuras para as quais a contagem de quadradinhos não seria uma boa estratégia. Objetivávamos identificar se as participantes adotariam novas táticas para determinar a área dada.

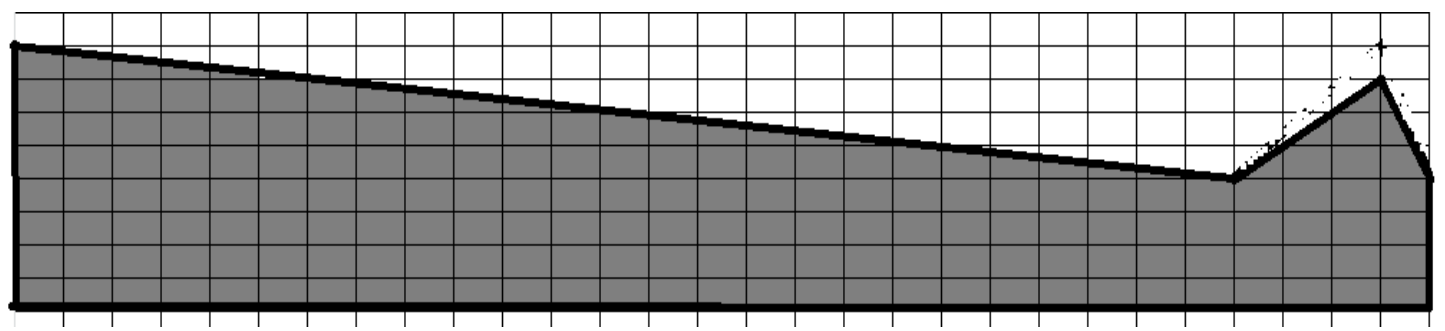

Figura 7 - Atividade proposta para ampliar as concepções sobre como determinar a medida de área Fonte: Acervo da Pesquisa

Ao analisarem a primeira figura (Figura 7), as professoras ainda tentaram "completar os quadradinhos", de modo que pudessem "reorganizar" a figura, mas perceberam que, para alguns casos, isso não seria tão imediato quanto nas situações anteriores.

A professora Acácia iniciou a resolução da questão contando os quadradinhos, mas, em um dado momento, estimou a compensação para chegar a um retângulo (Figura 8); no final ela declarou: "A medida aproximada da área dessa figura está entre 179 e 180. Não, não, acredito ser 180, pois existe uma possibilidade maior de estarem preenchidos 180 quadradinhos" (professora Acácia).

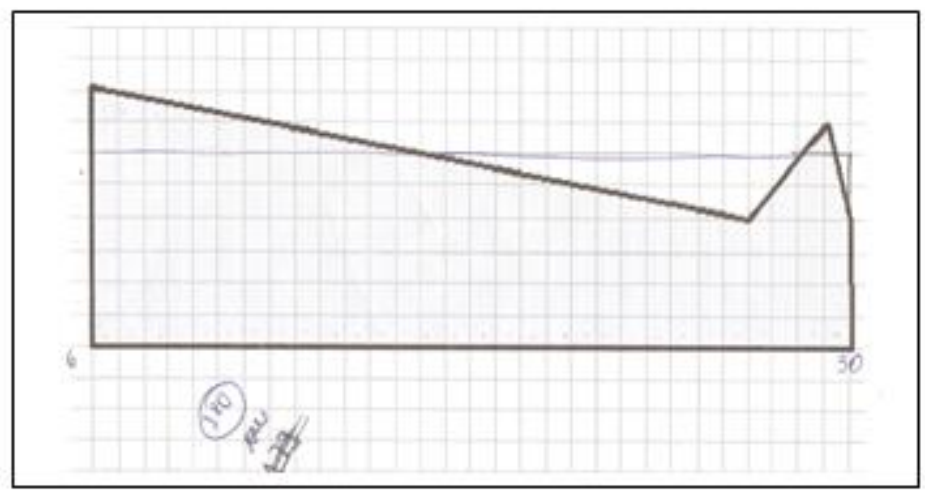

Figura 8 - Protocolo apresentado pela professora Acácia Fonte: Acervo da Pesquisa

Professora Violeta, assim como a professora Acácia, tentou completar e contar os quadradinhos, mas, do mesmo modo, percebeu que não conseguiria compensar os quadradinhos em alguns casos (Figura 9); também estimou a área da figura em 179 "quadradinhos". 
DOI: $10.20396 /$ zet.v28i0.8652733

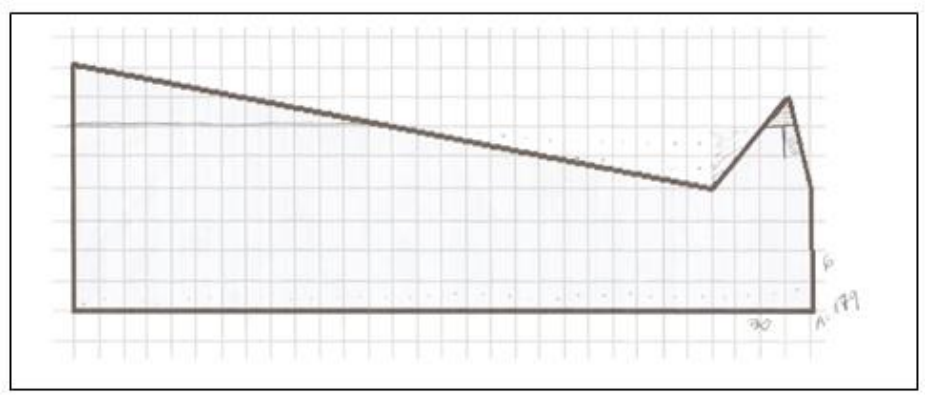

Figura 9 - Protocolo apresentado pela professora Violeta Fonte: Acervo da Pesquisa

A professora Watsonia, por sua vez, começou a perceber que a figura poderia ser dividida em retângulos, iniciando um processo de análise "macro" da figura. Verifica-se que ela começou a analisar outras possibilidades de resolução para obtenção da área dada (Figura 10). Apesar de suas novas percepções, ela não conseguiu chegar ao resultado da área pedida e, assim como as outras professoras, estimou a medida em 180 "quadradinhos". A quarta participante de nossa pesquisa, a professora Jasmim, não participou da análise dessas figuras.

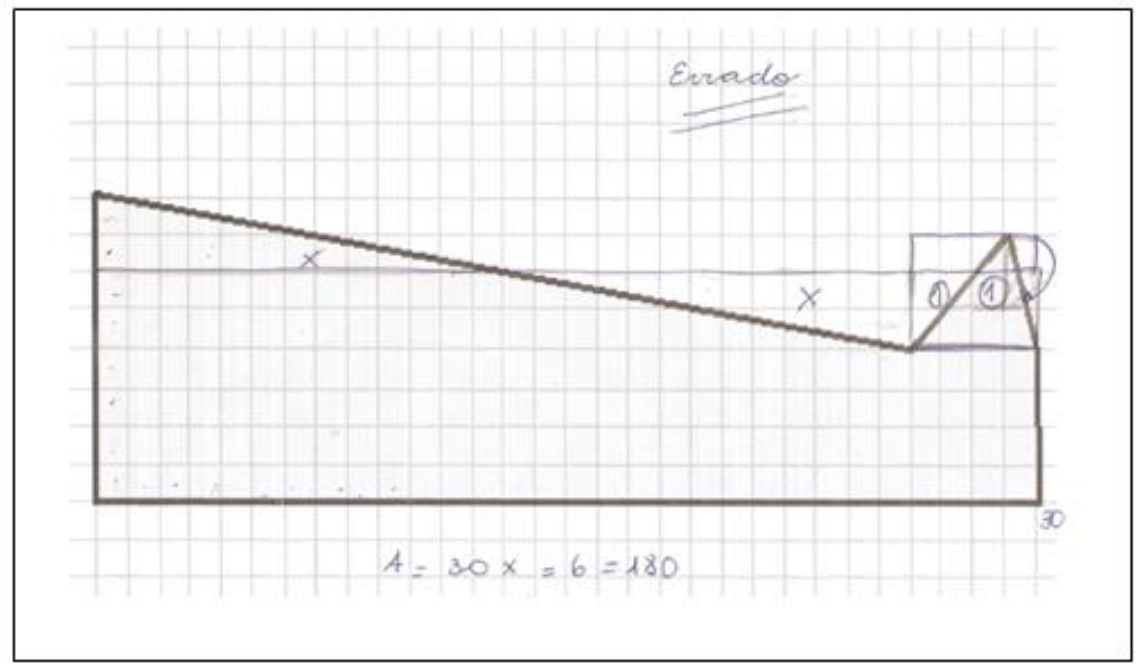

Figura 10 - Protocolo apresentado pela professora Watsonia

Fonte: Acervo da Pesquisa

Constatando que a professora Watsonia havia encontrado um "novo" caminho para a análise de área, estimulamos as participantes a analisar a figura como um todo, e até mesmo a dividi-la em retângulos e triângulos para facilitar a determinação da medida de área (Figura $11)$. 


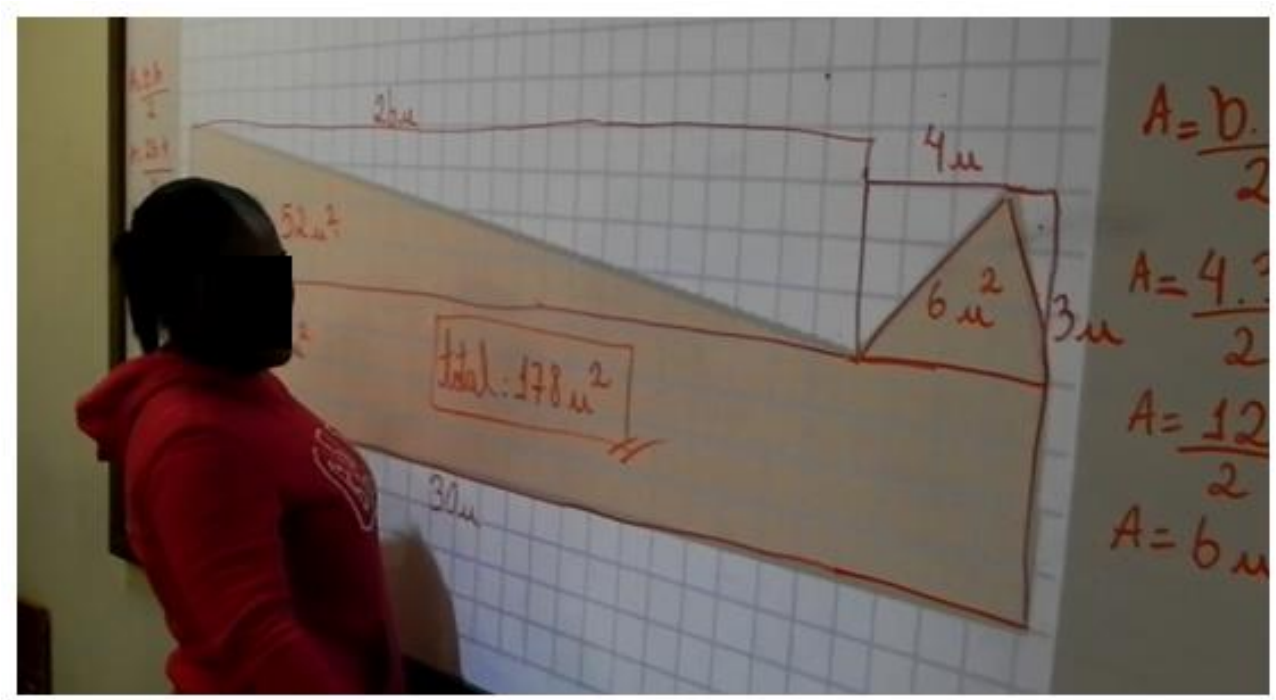

Figura 11 - As participantes mostram como ampliaram seus conhecimentos ao começarem a utilizar fórmulas Fonte: Acervo da Pesquisa

Ao perceberem que existia um método mais fácil para determinar a medida de área das figuras, as participantes iniciaram o processo de decompor as figuras em triângulos, quadrados e retângulos, para calcular a área das partes e, posteriormente, agrupá-las para identificar a área da figura toda. Então, para analisar a compreensão das participantes a respeito desse "novo" processo, apresentamos as outras duas figuras (Figura 12), com o mesmo objetivo da questão anterior.
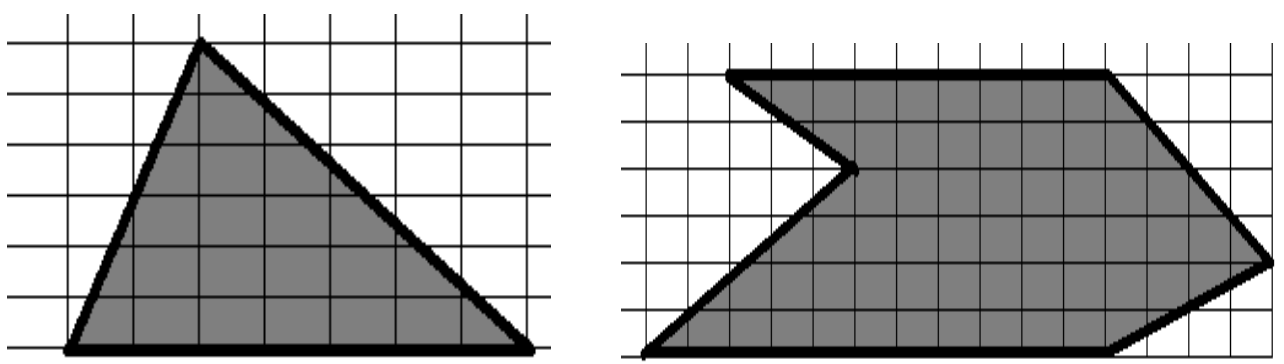

Figura 12 - Figuras utilizadas na formação para ampliar as concepções sobre a determinação da medida de área Fonte: Acervo da Pesquisa

Verificamos, durante as sessões de formação, que nossas participantes construíram um "novo" conhecimento, e não foi somente acerca do método de determinação da medida de área. Parte do grupo percebeu que cada figura podia ser analisada compondo e decompondo figuras, e não apenas contando os quadradinhos que estavam completamente preenchidos pela figura e estimando as demais partes.

Acácia, por exemplo, iniciou o processo contando os quadradinhos, mas logo se deu conta que esse procedimento a ajudaria apenas a estimar a medida da área, e não lhe indicaria a medida exata. Então tentou formar um retângulo de dimensões $6 \mathrm{u} \times 4 \mathrm{u}$, e percebeu que 
DOI: $10.20396 /$ zet.v28i0.8652733

havia outro maior que poderia conter o dado triângulo. Foi então que nossa participante dimensionou as medidas de retângulo para $6 \mathrm{u} \mathrm{x} 7 \mathrm{u}$, que eram exatamente a medida da base pela altura do triângulo. Ela notou também que a área encontrada era exatamente o dobro da área do triângulo que ela desejava encontrar, então dividiu essa medida por dois. Acreditamos que, nesse ponto do processo formativo, uma representação da fórmula de área do quadrado e do triângulo começou a fazer sentido para a participante.

Ao analisar a segunda figura, Acácia sentiu mais segurança ao apresentar seus cálculos. Ela percebeu que a figura podia ser dividida em três triângulos e um quadrado, o que em seu ponto de vista "facilita o cálculo da área quando dividimos a figura em partes, calculamos as áreas dessas partes e depois somamos seus resultados" (professora Acácia).

A professora observou também que as fórmulas aceleraram o processo de cálculo para obtenção de área e declarou: "Agora os resultados são obtidos mais rapidamente, pois não precisamos mais ficar contando os quadradinhos ...isso muda toda a visão que tinha sobre a fórmula e o que realmente ela representa" (professora Acácia). Foi possível observar que a professora Acácia, nesse momento, mostra domínio dos conhecimentos comuns relativos à configuração retangular como elemento importante no cálculo de área do retângulo por meio da fórmula e dos conhecimentos especializados do processo de decomposição do retângulo para chegar à fórmula do triângulo e, mais geralmente, para calcular a área da figura.

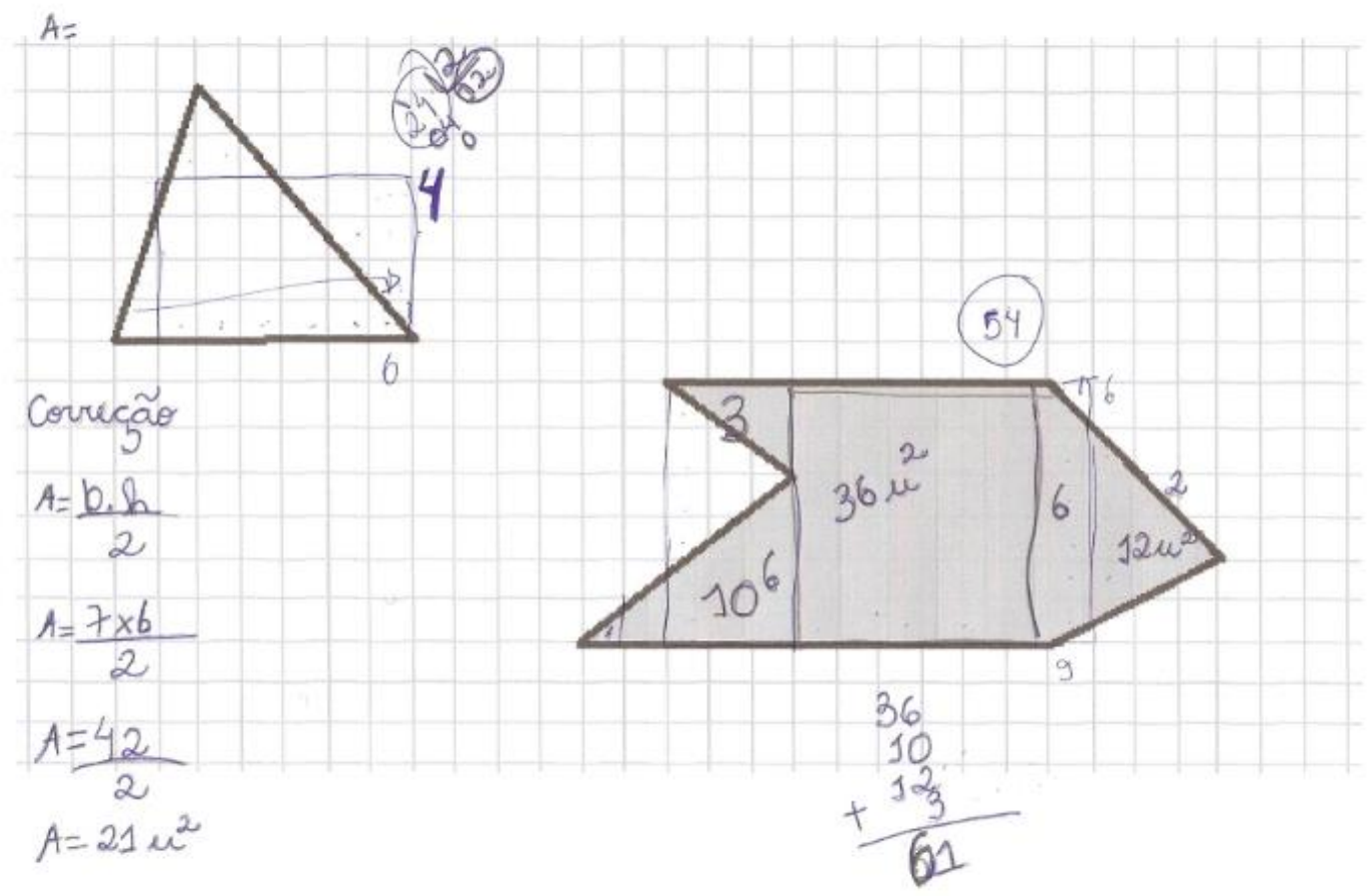

Figura 13 - Protocolo apresentado pela professora Acácia Fonte: Acervo da Pesquisa

A professora Watsonia declarou e escreveu no início da discussão que não sabia resolver a situação dada, mas, encorajada pelo grupo, conseguiu na tentativa inicial compreender que o triângulo, na primeira figura, poderia estar contido em um retângulo de $6 \mathrm{u}$ 
DOI: $10.20396 /$ zet.v28i0.8652733

$\mathrm{x} 7 \mathrm{u}$, e também reconheceu que essa área era exatamente o dobro da medida de área do triângulo, então ela dividiu esse valor por dois. Assim como a professora Acácia, formalizou essas informações por meio das fórmulas de área do retângulo e do triângulo (Figura 14).

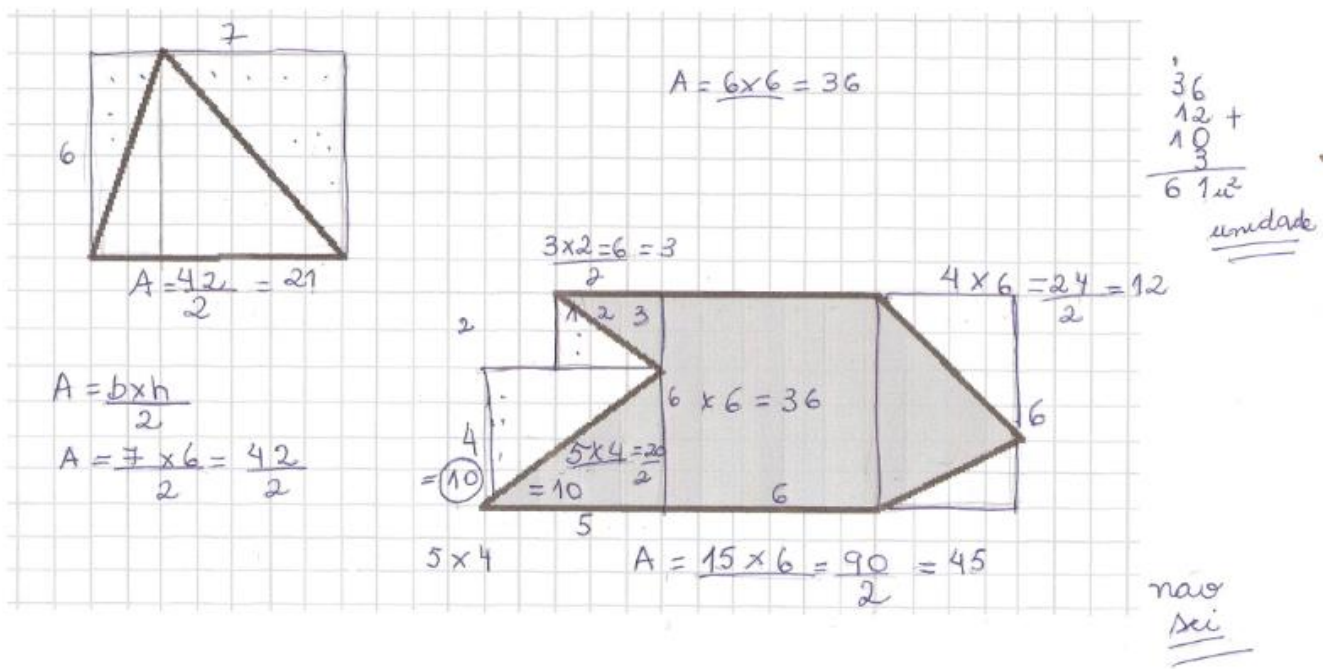

Figura 14 - Protocolo apresentado pela professora Watsonia Fonte: Acervo da Pesquisa

A terceira participante, a professora Violeta, mesmo sendo encorajada pelo grupo, teve muita dificuldade, ao analisar as questões solicitadas (Figura 15).

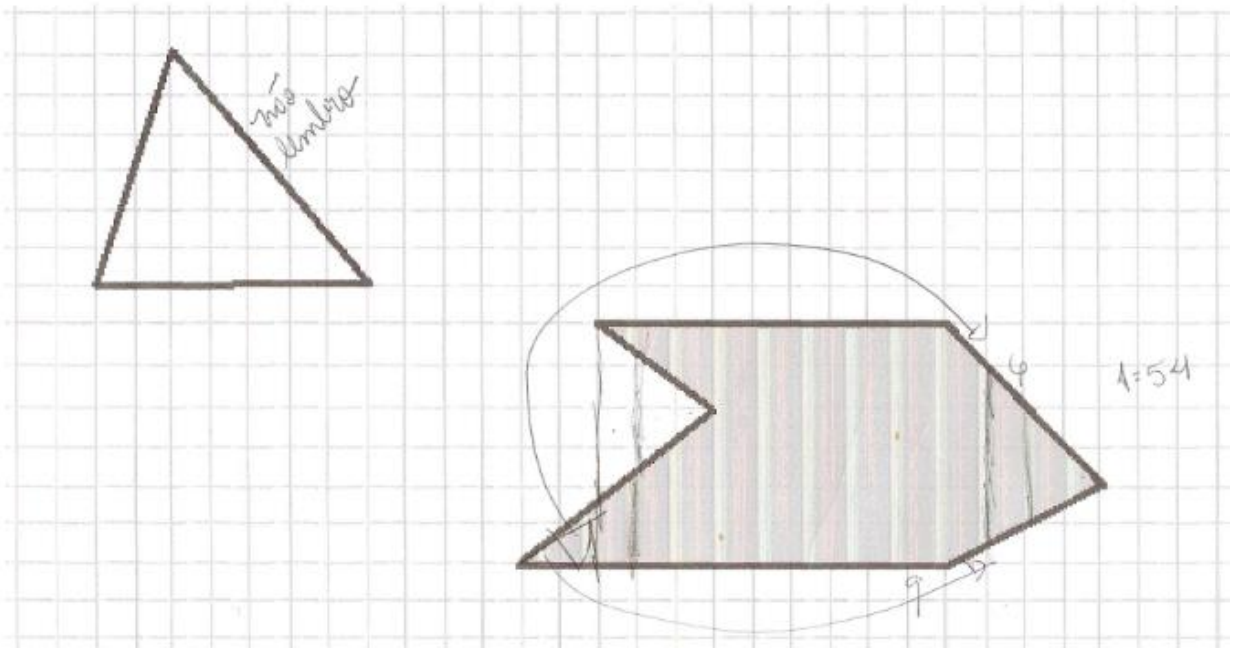

Figura 15 - Protocolo apresentado pela professora Violeta

Fonte: Acervo da Pesquisa

Para deixar a professora Violeta mais à vontade, e para que ela e as demais participantes pudessem construir e fortalecer o novo conhecimento por meio da percepção de retângulos, solicitamos que elas explicassem como elas haviam conseguido chegar ao resultado (Figura 16). 


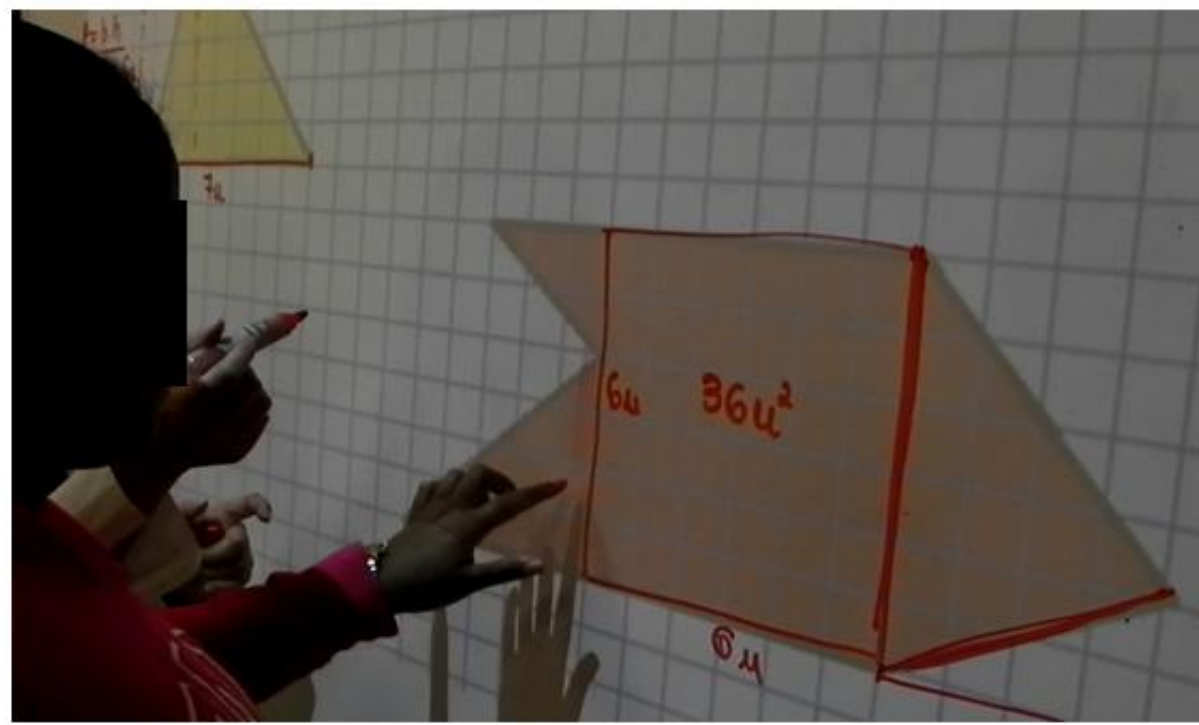

Figura 16 - Esclarecimento sobre como as professoras utilizaram as fórmulas para determinar a medida de área Fonte: Acervo da Pesquisa

Após a explanação das outras duas participantes, a professora Violeta conseguiu compreender e ajudar no processo de separação e reconfiguração da figura para obtenção da área total, processo esse importante para proceder o ensino - Conhecimento Especializado do conteúdo como descreve Ball et al. (2008). Nesse momento, elas discutiram sobre essa outra estratégia de cálculo da medida de área:

Profa. Acácia: Vocês perceberam que fica mais fácil olhar para área quando transformo em retângulos.

Profa. Violeta: Verdade, mas você tem que olhar para fora da figura, eu estava errando.

Profa. Watsonia: Retângulo é fácil é só ver quantas fileiras eu tenho de quadradinhos. Profa. Acácia: Verdade, base vezes altura. E quando tem triângulo eu também posso transformar em retângulo.

Profa. Violeta: Nunca pensei em olhar para a fórmula desse jeito.

Profa. Jasmim: Hoje aprendi mais uma forma de olhar para área [referindo-se ao cálculo de área em malha quadriculada].

No início do diálogo professoras Acácia e Violeta, quando consideram o triângulo como parte do retângulo, mostram evidências da ampliação do conhecimento especializado de matemática para ensinar área de figuras planas como descrevem Ball et al. (2008, p.394), uma vez que o conhecimento sobre diferentes formas de composição de áreas é, como dizem os autores, essencial à realização do ensino, por isso "[...] intimamente relacionado com a prática"”. As professoras Acácia e Violeta recorreram ao que Duval (1994) denomina como mergulhamento ${ }^{10}$ quando relatam observar que fica mais "fácil" calcular a área "quando

\footnotetext{
9 “[...] closely related to practice” (Ball et al., 2008, p. 394)

${ }^{10}$ Segundo Duval (1994) Mergulhamento é uma operação ligada à apreensão operatória que consiste em inserir uma figura em outra figura de modo que a primeira se torne subfigura da nova.
} 
DOI: $10.20396 /$ zet.v28i0.8652733

transformo retângulos" ou quando observam a estratégia de "olhar para fora da figura". Além disso, elas, nesse momento, perceberam a importância de se formar um grupo de estudos dentro da unidade escolar: "Sozinha eu não teria essa percepção, estou aprendendo muito em nossos encontros" (professora Violeta).

Assim como nós, Etcheverria (2008) acredita que a formação de grupos de estudos constituídos na própria unidade escolar pode favorecer o desenvolvimento profissional dos participantes.

A partir da participação nos grupos de estudos, o educador tem a oportunidade de, na troca de ideias e vivências sobre o tema em estudo e discussão, (re)pensar a sua rotina de trabalho, desafiando-se a qualificar o processo de ensino. (p. 23)

Prosseguindo, a autora também enfatiza a reflexão que cada docente deve ter sobre sua prática de ensino:

Do relato e reflexão sobre as práticas, passa-se a conhecer a metodologia empregada pelo professor e os recursos que utiliza para alcançar os objetivos a que se propôs. Quando o docente reflete sobre o processo de ensino-aprendizagem que oportuniza e o seu papel nele, consegue compreendê-lo, faz interpretações das situações a ele relacionadas e também desenvolve autonomia necessária para reconstruí-lo. (p. 23)

Diante de todo o exposto na sessão de formação aqui descrita, podemos inferir que o conhecimento comum e especializado da determinação da área de figuras não retangulares, segundo Ball et al. (2008), a princípio, não era dominado pelo grupo que investigamos. No entanto, já nessa primeira sessão, constatamos ter havido avanços no tocante à determinação de áreas de polígonos e que, além do estudo, a colaboração e a confiança alavancaram a (re)construção desse conhecimento.

\section{Algumas conclusões e considerações finais}

Analisando esse resultado sob o ponto de vista de Ball et al. (2008), identificamos ter ocorrido uma ampliação do domínio do conhecimento comum, sobre a contagem de quadradinhos ao especializado do conteúdo, sobretudo da capacidade dos participantes em transitar pelo percurso de construção do conceito de área, a partir da contagem de quadradinhos à reconfiguração das figuras ou operação de mergulhamento e à identificação, na prática, das fórmulas de área correspondentes. Sob nosso ponto de vista, acreditamos que o domínio desses conhecimentos comum e especializado, provavelmente, contribuirá, de igual maneira, para a base de conhecimentos das professoras para o ensino de área de figuras planas. Nesse contexto, poderia, por exemplo, favorecer a ampliação do conhecimento do conteúdo e do ensino conforme descrito por Ball et al. (2008) que demandaria do profissional ter clareza do porquê propor cálculos de figuras planas que levem o aluno a vivenciar estratégias que fossem além da contagem de quadradinhos.

Julgamos que as experiências vivenciadas pelos professores aprofundaram seus conhecimentos tácitos a respeito da mobilização dos recursos associados à reconfiguração para calcular área em malhas quadriculadas para conhecimentos explícitos sobre o tema e, 
DOI: $10.20396 /$ zet.v28i0.8652733

nesse sentido, consideramos, assim como Serrazina (2012), que, possivelmente, tal fato contribuiu para aprimorar a base dos conhecimentos das professoras e, consequentemente, a sua capacidade de ensinar.

Pudemos ainda, fundamentados em Zeichner, observar o quanto foi relevante ouvir e refletir junto com as professoras sobre o ensino do conteúdo área de figuras planas. Foi por meio do apoio mútuo que elas identificaram suas próprias necessidades e modificaram suas análises acerca das estratégias a serem adotadas. Ainda, da mesma forma que o autor, pudemos verificar que esse processo ajudou a melhorar a compreensão desse grupo sobre a temática estudada e possibilitou-lhes ampliar seu desenvolvimento profissional.

Entretanto, ressaltamos a importância de a formação de grupos de estudo assumir um caráter de atividade permanente e se debruçar sobre os vários temas abordados ao longo da escolaridade, de forma a constituir-se um espaço frutífero de discussão e reflexão no ambiente escolar.

\section{Referências}

Ball, D. L., Thames, M. H., \& Phekps, G. (2008). Content knowledge for teaching: what makes it special? Journal of Teacher Education, 59(5), 389-407.

Baturo, A., \& Nason, R. (1996). Student teachers' subject matter knowledge within the Domain of Area Measurement. Educational Studies in Mathematics, 31(3), 235-268.

Brasil (1997). Ministério de Educação e Cultura. Secretaria de Educação. Parâmetros curriculares nacionais: primeiro e segundo ciclos do ensino fundamental: matemática. Brasília.

Brasil (2018). Ministério de Educação e Cultura. Secretaria de Educação. Base Nacional Comum Curricular. Brasília.

Clements, D. H., \& Stephan, M. (2004). Measurement in pre-K to grade 2 mathematics. In D. H. Clements \& J. Sarama (Eds.), Engaging young children in mathematics (pp. 299317). Londres: Lawrence Erlbaum Associates.

Duval, R. (1994) Les différents fonctionnements d'une figure dans une démarche geometric.Repères. IREM, 17, 121-137.

Etcheverria, T. C. (2008). Educação continuada em grupos de estudos: possibilidades com foco no ensino da geometria. Dissertação de Mestrado em Educação em Ciências e Matemática. Porto Alegre: Pontifícia Universidade Católica do Rio Grande do Sul. Disponível em: http://repositorio.pucrs.br/dspace/handle/10923/3006

Garcia Silva, A. F., Galvão, E. E. L., \& Campos, T. M. M. (2013). Uma interpretação das estratégias utilizadas por um grupo de professores ao calcular área de polígonos em malha quadriculada. Actas del VII CIBEM (pp. 5.674 - 5681). Madrid, Espanha. Retirado em 14 de outubro, 2020, de: http://www.cibem7.semur.edu.uy/7/actas/pdfs/1322.pdf

Gimeno Sacristán, J. (2000). O currículo: uma reflexão sobre a prática. 3. ed. Artmed.

Gomes, J.M., Galvão, M.E.L., \& Garcia Silva, M.E. (2018). O conceito de área num processo de formação de professores dos anos iniciais. Jornal Internacional de Estudos em 
DOI: $10.20396 /$ zet.v28i0.8652733

Educação Matemática, 11(3), 261-269. Disponível em: https://revista.pgsskroton.com/index.php/jieem/article/view/7060

Serrazina, L. (1999) Reflexão, conhecimento e práticas lectivas em matemática num contexto de reforma curricular no 1. ${ }^{\circ}$ ciclo. Quadrante, Lisboa, 8(9), 139-167.

Serrazina, M. L. (2012). Conhecimento matemático para ensinar: papel da planificação e da reflexão na formação de professores. Revista Eletrônica de Educação, 6(1), 266-283. http://www.reveduc.ufscar.br/index.php/reveduc/article/view/355

Shulman, L. (1986). Those who understand: knowledge growth in teaching. Educational Researcher, 15(2), 4-14.

Zeichner, K. (1993). Formação reflexiva de professores: ideias e práticas. Lisboa, Educa.

Zeichner, K. M. (2008). Uma análise crítica sobre a "reflexão" como conceito estruturante na formação docente. Educação e Sociedade [online], 29(103), 535-554. http://dx.doi.org/10.1590/S0101-73302008000200012. 